\title{
A LICHEN PLANUS ERUPTION AFTER ARSPHENAMIN *
}

\author{
LAWRENCE K. MCCAFFERTY, M.D. \\ NEW YORK
}

It is a well recognized fact that the administration of arsphenamin may produce definite dermatoses of which the most familiar type is the erythematous eruption, which in some instances develops into an exfoliative dermatitis.

Recently Queyrat, Louis, and Rabut, ${ }^{1}$ Kleeberg, ${ }^{2}$ Buschie and Freymann, ${ }^{3}$ and Keller, ${ }^{4}$ have reported cases of arsphenamin dermatitis with lichenoid lesions. The following case is reported because, following treatment by arsphenamin, the patient developed a condition which in its clinical appearance, in the histology of the lesions, and in the course of the disease was indistinguishable from true lichen planus. While the possibility that this was a mere coincidence cannot be excluded, the evidence to be presented favors the assumption that the eruption was caused by arsphenamin.

REPORT OF CASE

History.-A mulatto woman, aged 40, married, was admitted to the outpatient department of the Presbyterian Hospital, June 1, 1921, complaining of a skin eruption on the right forearm. The history was irrelevant except that her present husband had been under treatment for syphilis. The patient gave no history of primary or secondary syphilitic manifestations. She had suffered for six years from the lesion which was present on admission.

Physical examination revealed a gauntlet shaped eruption confined to the right forearm and hand. It extended from the finger tips to the middle of the forearm, on the extensor and flexor surfaces. The eruption was brownishred and did not disappear on pressure. The veins shone through. It was slightly scaly except on the palm, which showed a marked hyperkeratosis. The upper limit was serpiginous and extended completely around the forearm. The cervical nodes were palpable, the knee and ankle reflexes were hyperactive. The Wassermann test was four plus. The urine was negative.

* From the department of medicine of Columbia University College of Physicians and Surgeons, and the Preslyyterian Hospital.

1. Queyrat, Louis, and Rabut: Bull. Soc. franç. de dermat. et syph., 1921, No. 2.

2. Kleeberg, L.: Beitrag zur Klinik der Salvarsan Exanthema, Therap. Halbmonatsh. 35:370, 1921.

3. Buschke, A., and Freymann, W.: Lichen-ruber-ahnliche Salvarsan Exanthema, Med. Klin. 30:909, 1921.

4. Keller, Philipp: Lichen planus und lichenoide arsendermatitis, Dermat. Wchnschr. 74:9 (Jan. 7) 1922. 
Histology.-A biopsy from the affected area on the right arm revealed slight hyperkeratosis, and atrophy of the rete with a slight prolongation of the rete pegs. There was a slight cellular infiltration into the epidermis. The papillae and upper cutis were infiltrated with mononuclears, plasma and epithelioid cells. The infiltration was rather sharply demarcated in the upper cutis. The connective tissue of the papillae and upper cutis showed an interstitial and parenchymatous edema. The blood and lymph vessels were moderately dilated and surrounded by a sleevelike infiltration of plasma cells. The diagnosis was tertiary syphilid of the right hand and forearm.

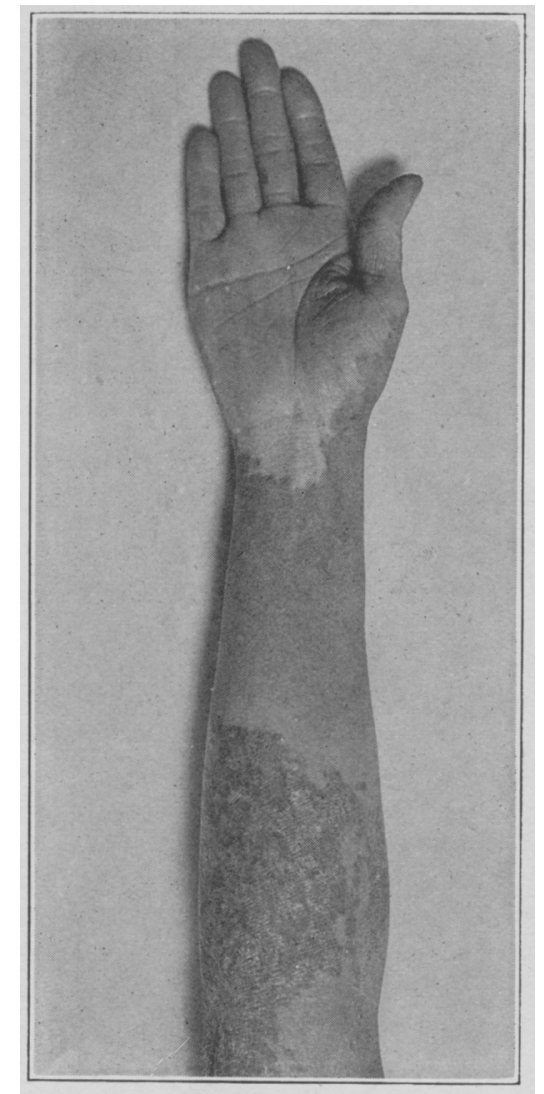

Fig. 1.-Leukoderma of right palm: The skin is normal from middle of forearm to palm. This was the only part of the body unaffected by the lichenoid eruption. It was the former site of the tertiary syphilid.

Trcatmont and Results.-The patient was given arsphenamin and mercuric salicylate at weekly intervals. She received nine intravenous injections of arsphenamin averaging $0.3 \mathrm{gm}$. each, and six 1 grain injections of mecuric salicylate intramuscularly. During the antisyphilitic treatment the tertiary syphilid cleared up. The skin of the forearm resumed a normal appearance, but the fingers became leukodermic in places. Within three or four hours after the third and each succeeding arsphenamin injection, the patient complained of a burning sensation 
in the stomach, and of belching of gas. This indicated arsphenamin intoxication. After the seventh arsphenamin injection, stomatitis, herpes of the lips and vaginitis developed. The mercurial injections were stopped. The ninth and last arsphenamin injection was given, September 1. At this time there were well defined, slightly raised, purplish-red plaques about $1 \mathrm{~cm}$. in diameter, on the left palm and sole. There were a few scattered, lentil-sized, violaceous, ill defined papules on the mesial surfaces of the arms and left axilla.

Second Admission.-As the eruption continued to develop and the patient complained of weakness and malaise, as well as the intense itching, she was admitted to the Presbyterian Hospital, September 8.

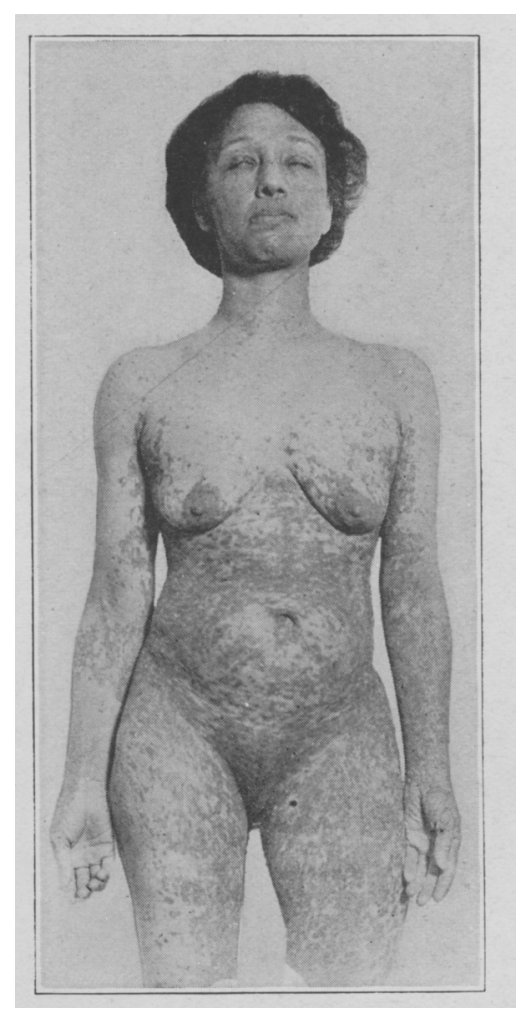

Fig. 2.-Lichenoid eruption: The face, neck and chest are practically clear, although a few lesions appear on the face. The right forearm shows the former site of the tertiary syphilid.

Physical examination disclosed slight lacrimation, inflamed nasal mucosa, and exfoliation of the lips. The tongue and buccal mucosa presented irregular raised grayish areas the size of a pea. The heart and lungs showed no evidence of disease; the liver edge was palpable, but in other respects the abdomen was negative. The systolic blood pressure was $120 \mathrm{~mm}$., the diastolic 70 . Blood urea, uric acid, and sugar were within normal limits. The blood count was as follows: erythrocytes, 5,100,000; leukocytes, 8,900; polymorphonuclears, 79 per cent.; small mononuclears, 6 per cent.; large mononuclears, 4 per cent.; eosino- 
phils, 11 per cent. The hemoglobin was 80 per cent. The blood platelets were normal. The urine showed no albumin, no pus, and no casts. Phenolsulphonephthalein excretion was 40 per cent. in two hours and fifteen minutes.

Two days later the eruption faded, but on September 17 it became more severe. The patient then began to improve rapidly, and was discharged, October 8 , with a diagnosis of syphilis and lichen planus.

Third Admission.-She was readmitted to the outpatient service, Nov. 7 , 1921, complaining of a generalized eruption consisting of shiny, angular papules

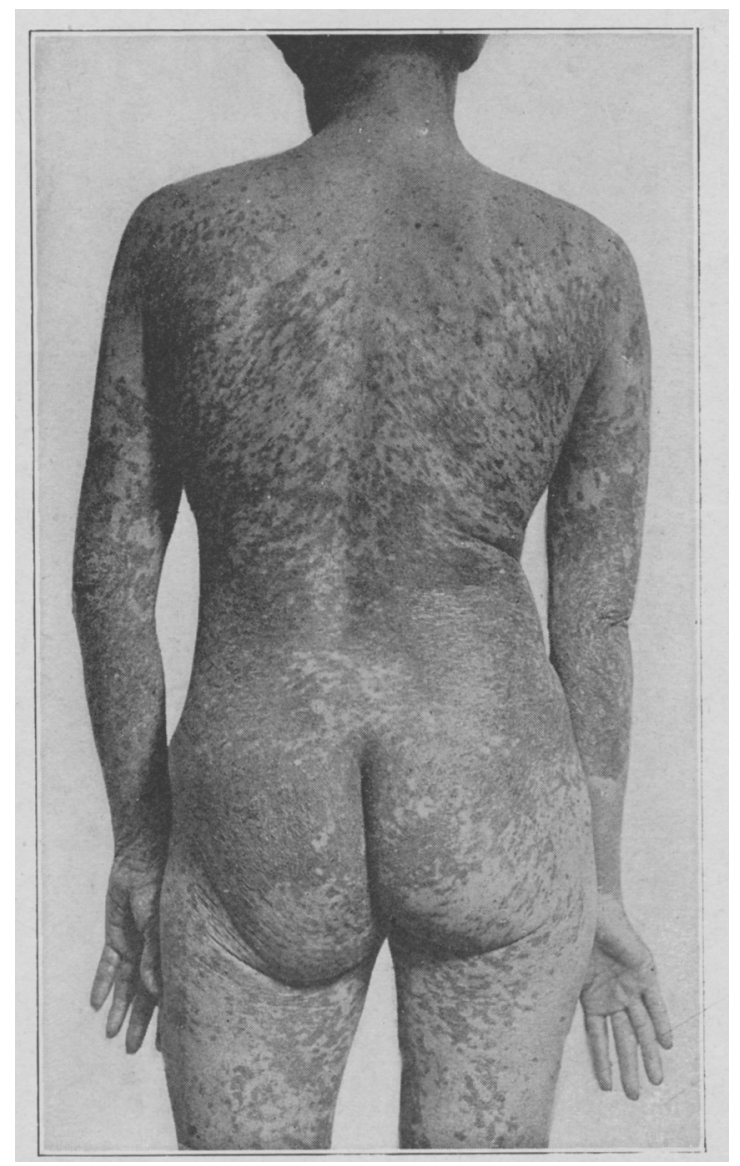

Fig. 3.-Lichenoid eruption. The papules have coalesced in many places, the coffee colored pigmentation is interspersed between many of the papules. The upper back and neck are reasonably clear.

from 3 to $5 \mathrm{~mm}$. in diameter, and from violaceous to deep purple. A few were distinctly umbilicated. These papules were diffusely scattered over the face and neck, the upper portion of the trunk, and the extensor surfaces of the arms. In other areas they hecame confluent, in some instances forming rings with yellowish-l)rown centers. Surrounding such patches were areas of yellowishbrown or slate colored pigmentation. The lesions were so numerous on the 
flexor surfaces of the arms, the axillae, abdomen, lower back, hips and inner surfaces of the thigh that little normal skin remained. On the extensor surfaces of the upper arms and lower legs there was slight follicular keratosis with pigmentation. The areolae of the nipples were deeply pigmented. The palms and soles showed hyperkeratosis. The nails were thickened and had pigmented longitudinal riclges along their entire length. The lower half of the right hand and arm, which was the site of the former syphilitic lesion, was free from lesions. The eyes lacrimated profusely. The entire mucous membrane of the mouth showed scattered minute grayish-white papules. Similar lesions were found in the vagina. The pruritus, which had been a marked symptom in the hospital, had subsided.

Biopsy.-Section of a lichenoid lesion removed while in the hospital revealed a marked hyperkeratosis with a dipping down of the horny layer into the epidermis, forming dells. There was a marked acanthosis with increased granu-

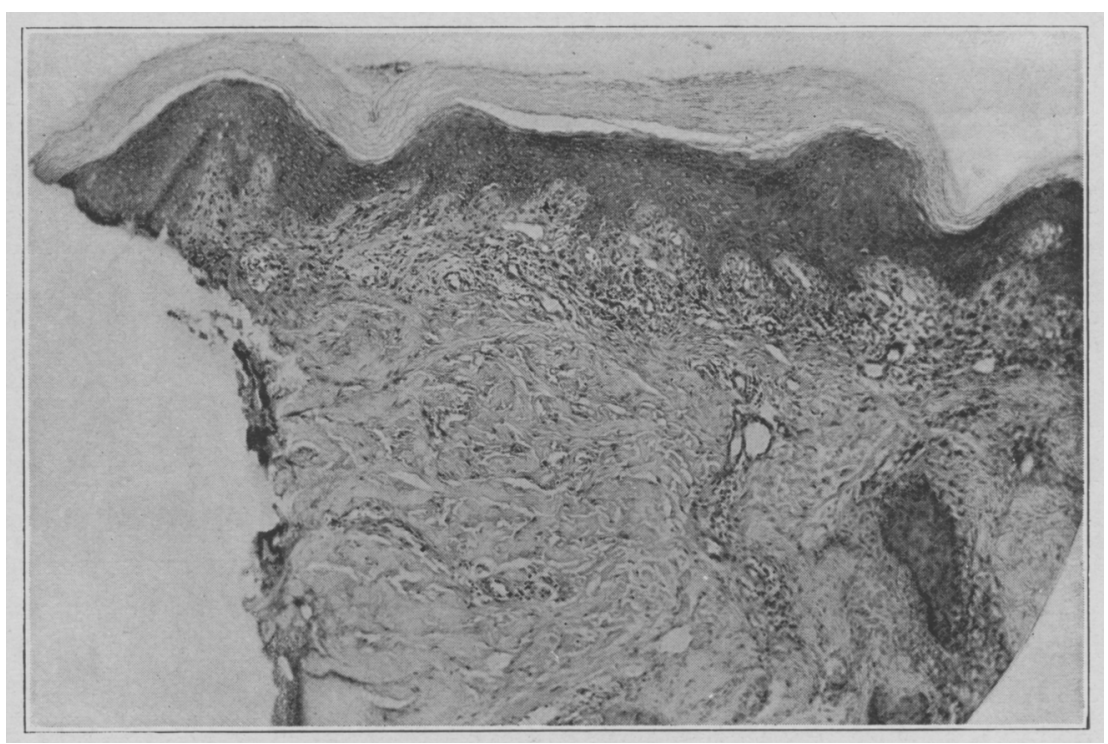

Fig. 4.- Section taken from a papule on the left forearm. Reduced from a photomicrograph $\times 118$.

lar layer, edema, and colloid degeneration of the rete cells. The papillae were widened and edematous. The upper cutis also showed edema. the blood and lymphatic vessels were dilated, and there was a marked cellular infiltration, sharply demarcated from the lower layers.

Cnder high power the infiltration of the upper cutis and papillac was seen to consist of small mononuclears, larger cells probably of connective tissue origin and melanoblasts, which alone contained pigment granules. The blood and lymphatic vessels of the lower cutis were surrounded by cellular exudate consisting chiefly of mononuclears (Fig. 4).

There was a gradual improvement in her condition, but when last seen, seven months after the first appearance of the lichen planus eruption. she still had a few papules. 


\section{COMMENT}

There seems little doubt that, had this patient presented the conclition just described and given no history of arsphenamin treatment, she would have been regarded as having lichen planus. In view of the fact that the eruption followed treatment, there are three possible interpretations: (1) That it was a mere coincidence. (2) That it was a dermatitis medicamentosa due to arsphenamin. (3) That it was a true lichen planus, in this instance caused by arsphenamin.

Lichen planus, clinically and histologically, is fairly well defined. We have no knowledge of the exact cause, but two hypotheses have been advanced: Pollitzer," Lieberthal," and Hazen ${ }^{\top}$ believe it is a microbic infection. White, ${ }^{\star}$ believes that the disease has a neurotic basis. He states that "lichen planus occurs more frequently in educated men and women whose lot in life has been hard." Little, ${ }^{9}$ comparing the incidence of lichen planus before and during the war, found a decrease in the latter period, a fact which seems to argue against a neurotic basis. Neither of these hypotheses has any definite proof. Considering the want of knowledge of the cause of lichen plants, this case in which the same syndrome followed arsphenamin intoxication is not without interest.

Previously Reported Cases.-In considering the possibility of arsphenamin causing this eruption, it should be recalled that lichenoid lesions due to arsenicals have been described previously. As far back as 1902, Brooke and Roberts, ${ }^{10}$ as well as Barendt, ${ }^{11}$ described such lesions occurring in an epidemic of arsenical poisoning from beer. Gans, ${ }^{12}$ describing the histology of arsenic melanosis, writes of a case in which the histologic picture was characteristic of lichen planus. This case showed hyperkeratosis, edema of the papillary bodies and a sharply demarcated infiltration of the upper cutis with mononuclears and mast cells. Pigment was scattered through the epidermis, papillae, and upper cutis.

5. Pollitzer, S.: J. Cutan. Dis. 37:682 (Oct.) 1919.

6. Lieherthal, D.: J. Cutan. Dis. 37:682 (Oct.) 1919.

7. Hazen, H. H.: Diseases of Skin, St. Louis, The C. V. Mosby Co., 1915, p. 394 .

8. White, C. J.: Lichen Planus, J. Cutan. Dis. 37:671 (Oct.) 1919.

9. Little, E. G.: Lichen Planus, J. Cutan. Dis. 37:639 (Oct.) 1919.

10. Brooke, H. G., and Roberts, L.: The Action of Arsenic on the Skin as Observed in the Recent Epidemic of Arsenical Beer Poisoning, Brit. J. Dermat. 13:120 (April) 1901.

11. Barendt, F.: The Skin Lesions Due to the Presence of Arsenic in Beer. Brit. J. Dermat. 13:148 (April) 1901.

12. Gans, Oscar: Zur Histologie der Arsenmelanose, Beitr. z. path. Anat. u. z. allg. Path. 60:22, 1914-1915 
Since the widespread use of arsphenamin more typical cases have been reported. Queyrat, Louis and Rabut described an eruption on the tongue resembling lichen planus, clinically and histologically, which occurred after the administration of galyl, a drug similar to arsphenamin. The patient also developed an erythema and pigmentation of the body with intense itching.

Kleeberg also reported a case with an eruption on the dorsum of the hands, and lesions of the buccal mucosa resembling lichen planus following a third course of arsphenamin therapy. Buschke and Freymann reported two cases of acute generalized lichenoid eruption occurring during arsphenamin treatment. Their first case had papules on the chest and flexor surfaces of the extremities resembling lichen planus. The entire skin had a silvery, shiny appearance, felt like a nutmeg grater, and resembled lichen planus verrucosus. Histologically the epithelium was slightly changed. The corium was infiltrated with mononuclears and polymorphonuclears, principally in the perivascular spaces. In the second case, the trunk, flexor and extensor surfaces of the extremities were involved, and the face, neck and chest were free. There was a diffuse grayish-brown to coffee colored pigmentation with a varying degree of intensity. The legs presented follicular keratosis with atrophic centers. The histologic picture revealed normal epithelium, a mononuclear infiltration sharply limited to the upper cutis and brownish-black pigment in the papillae. According to the atthors, their first case showed a nonspecific inflammation, while their second case resembled lichen planus histologically, but not clinically. At a little later clate Buschke and Freymann, ${ }^{13}$ reported a third case which resembled lichen planus somewhat. The eruption was not preceded by a dermatitis but by a slight icterus. Shiny red papules were grouped in rings on the sides of the extremities. Some of these papules occurred along linear scratch marks. There were also macules, follicular papules, and pustu'.es. Biopsy revealed only a slight polymorphonuclear infiltration in the cutis under a somewhat acanthotic epidermis. Hoffman ${ }^{14}$ described, as a case of lichen planus, an eruption on the body and buccal mucosa, which appeared after the cessation of antisyphilitic treatment. The patient was given arsphenamin again and the lichen planus eruption became more severe. Sections of a typical papule were characteristic of lichen planus. Keller reported a case which, he said, was lichen planus clinically and histologically. His patient had an eruption confined to the face, body and extremities. There was a diffuse

13. Buschke, A., and Freymann, W.: Weiterer Beitrag zu den Lichenruberähnlichen Exanthemen nach Salvarsan, Dermat. Wchnschr. 73:945 (Sept. 10) 1921.

14. Hoffman, E.: Arsenkeratose nach hochgradigen universellen Exanthem durch Sulosozylat, Tr. Bonn. Niederrh. Gesellsch., May 9, 1921. 
brownish-red pigmentation with a network of split pea sized rerldishbrown shiny papules, and there were characteristic lesions of lichen planus on the buccal mucosa opposite the last molar. Smith ${ }^{15}$ presented a case before the American Dermatological Association in which an exfoliative dermatitis developed following two courses of arsphenamin. In the discussion of this case it was brought out that some lesions strongly resembled lichen planus. One case of exfoliative arsenical dermatosis with hyperkeratosis reported by Schäfer ${ }^{16}$ also presented lesions on the tongue and buccal mucosa which were somewhat like lichen planus. The chief involvement in this case was on the covered parts of the body, which showed a diffuse pigmentation, but in the pigmented areas lichen like papules were also found. Similar cases of arsenical melanosis were studied by Gans and by Habermann. ${ }^{17}$

In all of the cases cited, arsenic was considered undoubtedly the cause of the eruption. In no case was the clinical appearance as close to that of an ordinary lichen planus as in the case reported here. Altogether they form strong evidence for believing that arsenic may produce an eruption simulating this disease. That the eruption described was caused by arsenic was indicated by slight symptoms of arsenic poisoning during a course of treatment, and also by symptoms which are common in arsenic poisoning and are not associated with ordinary lichen planus: conjunctivitis, stomatitis, ${ }^{18}$ and palmar keratosis. The pigmentation which was pronounced in this case occurs both in true lichen planus and in frank arsenical dermatitis. In acute generalized lichen planus the papules coalesce and on involuting leave a dark pigmentation which may be confluent. In the case described, however, there was some pigmentation preceding the appearance of papules. This sequence of events has been observed by Jadassolnn ${ }^{19}$ in true lichen planus.

\section{SUMMARY}

1. This case presented the clinical and histologic picture of lichen planus.

2. The eruption followed shortly after the administration of arsphenamin.

3. Cases of arsenical dermatitis closely simulating lichen planus have previously been described.

4. In the case reported, symptoms and lesions of arsenical poisoning support the belief that arsphenamin caused this eruption.

15. Smith, Morton: Arch. Dermat. \& Syph. 4:554 (June) 1921.

16. Schäfer: Einen Fall von exfoliativer Arsendermatitis und Hyperkeratose. Dermat. Zentralls. 2:426, 1921.

17. Habermann, R.: Dermat. Ztschr. 30:63, 1920.

18. Laurentier, C.: Bull. Soc. franç. de dermat. et syph. 6:276, 1921.

19. Jadassohn, quoted by Habermann (Footnote 17). 